\title{
Correction to: Classification of thermal image of clinical burn based on incremental reinforcement learning
}

\author{
Xianjun $\mathrm{Wu}^{1} \cdot$ Wendong Huang ${ }^{2} \cdot$ Xiaoli $\mathrm{Wu}^{3} \cdot$ Shenghang $\mathrm{Wu}^{4} \cdot$ Jinbo Huang ${ }^{2}$
}

Published online: 16 May 2021

(C) Springer-Verlag London Ltd., part of Springer Nature 2021

\section{Correction to: Neural Computing and Applications}

https://doi.org/10.1007/s00521-021-05772-7

Tshe corresponding author of the article is wrongly published and it is corrected as Dr. Jinbo Huang. This is corrected in the Original article as well.
Publisher's Note Springer Nature remains neutral with regard to jurisdictional claims in published maps and institutional affiliations.

The original article can be found online at https:// doi.org/10.1007/s00521-021-05772-7.

Xianjun $\mathrm{Wu}$ and Wendong Huang contribute equally to this work.

Jinbo Huang

jinbohuang_7582@21cn.com

Xianjun $\mathrm{Wu}$

wuxianjun@gdupt.edu.cn

1 School of Computer Science, Guangdong University of Petrochemical Technology, Maoming 525000, Guangdong, China

2 Scientific Research Center, The People's Hospital of Maoming City, Maoming 525000, Guangdong, China

3 Burn Department, The People's Hospital of Maoming City, Maoming 525000, Guangdong, China

4 Lap Wai Yuchai Power Machinery Co., Ltd., Zhuhai 519000, Guangdong, China 